\title{
Enthusiastic Academic and Support Service Staff as an Agent for Change: A Case Study Based on a Project in African Higher Education Institutes
}

\author{
Ari Haaranen and Jarmo Saarti \\ University of Eastern Finland, Kuopio, Finland \\ ari.haaranen@uef.fi \\ jarmo.saarti@uef.fi \\ DOI: 10.34190/EJEL.20.18.1.001
}

\begin{abstract}
The aim of this case study was to evaluate whether there had been educational changes and if so, in which phases of implementation and institutionalization in three African higher education institutions. The changes were evaluated from the point-of-view of trainees in the field of e-learning and library services during the project conducted in 2013-2015. Written texts and visual material were analysed using qualitative content analysis. The enthusiasm and mutual pedagogical understanding of the academic and support service staff were the key factors promoting the changes in the integration of e-learning and modern library services into everyday practices in these higher education institutions. The provision of suitable training and pedagogic skills to the academics and the support service staff made it possible dovetail these concepts to suit their home institution and provide them with a common language and value base that supported student learning.
\end{abstract}

Keywords: case study, development, educational change, e-learning, higher education, library, pedagogy

\section{Introduction}

\subsection{Globalization of higher education}

Higher education has changed in all parts of the world during the past decades. Globalization has increased our interconnectedness; this is evident in marketing, communication, cross-border mobility and information sharing. All of these changes have had a major impact on institutes providing higher education. At the same time, higher education is a notable participant in the global knowledge-based economy. (Marginson and van der Wende, 2007; Adams and de Wit, 2011). Today's communication technologies have made it possible to exploit e-learning and electronic access to the scientific documents and information, increasing their availability for teaching and learning in universities and colleges in even remote locations (Altbach, Reisberg and Rumbley, 2009). However, according to Courtney (2013), adapting to this change is still proving to be a challenge for higher education institutions: how can they handle the growth of new technologies, the explosion of information and global competitiveness and integrate these concepts appropriately into their curricula.

In Africa, higher education has expanded rapidly in recent years and there is a clear willingness to revitalize and harmonize higher education throughout the continent. The African Union (AU) views education as a crucial tool for Africa's development both from the perspective of quality and magnitude. Thus, the AU has strived to mobilize and support educational reform. The implementation of the Second Decade of Education for Africa's Plan of Action 2006-2015 is progressing slowly but surely and it has started to change education throughout the whole continent (AU, 2014). In higher education, the implementation has focused on four areas: the promotion of research and knowledge production, quality assurance, support for economic development and improved funding.

The Association for the Development of Education in Africa (ADEA) has published its Medium-Term Strategic Plan 2013-2017. This stressed that scientific and technological skills will be critical for achieving sustainable development and growth of Africa. This plan requires that the higher education system is reformed and ADEA has made efforts to promote transformational change throughout the many countries and regions of the African continent. (ADEA, 2013.) To achieve this change, ADEA has defined five strategic objectives: 1) to contribute to advancing policies, strategies, practices and programs, 2) to promote African-led education and training solutions to address national and regional needs, 3) to foster greater utilization of relevant ICT to 
accelerate the transformation of education and training approaches and outcomes, 4) to create a diverse and sustainable partner network and 5) to strengthen organizational capacity and effectiveness (ADEA, 2013.)

However, the monitoring and evaluation of the Plan of Action have revealed that most higher education institutions are more oriented towards teaching than research, even although the latter plays an important role in the production of knowledge and the creation of innovations (AU, 2014). Secondly, even though there has been a rapid expansion of higher education, this has not been matched by improved employment opportunities for graduates, especially in the low-income, Sub-Saharan African countries. Traditionally, almost 80 percent of the higher educated individuals are employed within the public sector that is at the moment expanding only slowly and even the more rapidly growing private sector cannot absorb all of the graduates.

There does seem to be a mismatch between the needs of commercial enterprises and the degree courses offered by the higher education institutions. (Majgaard and Mingat, 2012). According to Ndulu (2014) this is also one major reason why young highly skilled professionals migrate to the developed world. Lastly, ICT has been expected to increase access to education and improve the quality of education in Africa. However, the most African countries have faced challenges to achieving the expected benefits. According to Souter, et al. (2014) these challenges have been the absence of comprehensive policies, lack of ICT investments, limited infrastructure and support the use of ICT in education, lack of necessary ICT skills and lack of up-to-date data.

The European Bologna Process, one of the major recent reforms in higher education, has also affected nonEuropean regions like the African continent (Vögtle and Martens, 2014). For example, many African countries have switched to two-semester academic years, three-cycle study programmes and the change in the curricula to a system based on course credits (Sall and Ndjaye, 2007). This adoption of the Bologna Process has eased the North-South inter-academic cooperation, although it may be viewed as following in the footsteps of the former colonial powers. However, it has also provided models to improve the African inter-academic cooperation and networking in higher education. The balance between these demands and the development of quality in higher education is challenging but not impossible. (Sall and Ndjaye, 2007.)

In summary, higher education in Africa is now becoming integrated into the global higher education edifice. There are plans and strategies to develop higher education and know-how in many countries. Younger academics have obtained a high-quality education and they understand the importance of global academic networks. The developed world and its academics can actively support their African colleagues in their collaboration efforts. At present, human-kind is facing various global challenges which can only be resolved by global collaboration.

\subsection{Academics at the middle of change}

The academic staff has to appreciate and adopt all of the reforms and educational changes. How enthusiastically they implement these changes is related to their commitment to change and their job satisfaction. Thus, it is crucial to involve academics when new strategies are being planned and changes implemented. (Kindelan and Martin, 2014.) This literature review is focused on the academics in Europe and Africa.

In the past ten years, the role of the academic staff has changed dramatically. The increasing demands for excellence in teaching and research and the need to perform other non-academic tasks such as administrative work, quality assurance, counselling of students and marketing have become a part of the daily duties of many academics (Mapesela and Hay, 2006; Ylijoki, 2014). According to Ylijoki (2014), these changes can create a working environment, where the academics are compelled to work against their own values which obviously adds to their feelings that they are burdened with an excessive workload.

Many reforms and changes in the higher education have been initiated at the institutional or (inter)national levels, in which the academics have not had any say or clear role (Ylijoki, 2014). Usually, they have been encouraged, even forced, to adopt different kinds of standards in their teaching and research. This can be a reason for the result reported by Louvel (2013), who noted that academics in France did not adhere to the predetermined intention about how the planned curriculum change in higher education should be implemented. It indicated that academics used existing resources and networks of colleagues to cope with their changing roles. Thus the renewal process was more a result of trial and error rather than being a predetermined plan, complicated by the fact that success or failure could usually be only be assessed many years after the implementation of the reform. (Louvel, 2013.) 
Secondly, according to $\mathrm{Ng}^{\prime}$ ambi and Bozalek (2013) informal leaders have a major role in adapting new innovations such as emerging technologies in the higher education institutions in South Africa. They act as opinion leaders and agents for change, and their motivation for the use of technology seems to be intrinsic.

Ng'ambi and Bozalek (2013) recommended that these individuals should be viewed as executors of innovative practices, but they still require formal leadership which should formulate policies supporting the deployment of new technology in the home institutions. They also acknowledged that inadequate access to the internet and the lack of computers were the greatest institutional and individual constraints as were the lack of support, even resistance, from colleagues, as well time management problems. (Ng'ambi and Bozalek, 2013.)

The role of the deployment of new technologies such as e-learning has been evaluated as an agent of change in higher education institutions (HEIs). According to Salmon (2005) change can only succeed if e-learning is introduced into traditional teaching through centralization and provision of professional services or by implementing easy-to-use technologies backed up by investment in personal and departmental learning and development. Salmon stated that it is crucial to keep "ownership" of these technologies with the academics and their departments since only in this way will they develop their capacities over the longer term. (Salmon, 2005.) Ertmer and Ottenbreit-Leftwich (2010) have said that the implementation of new technologies in education requires teacher knowledge change, teacher beliefs change and teacher culture change. This will happen only, if HEls support changes by creating a culture which allows teachers to try out new practices and get technical and pedagogical support. Teaching is not effective without an appropriate use of ICT; it adds student-centered practices and binds support service staff into education. (Ertmer and Ottenbreit-Leftwich, 2010.)

\subsection{Description of project focusing on this case study}

This study describes the educational changes occurring in three African higher education institutions (HEIs) from the point-of-view of e-learning and library services. The study is based on two projects "Improving the Quality of Higher Education in Public Health Sciences" (HEPHS I and II) which were implemented during the period of 2011-2016. The main aim of these collaborative projects was to improve higher education in public health sciences. Three African universities participated in different aspects of these projects, one of which was from North Africa and two from the Sub-Saharan part of Africa. The project was coordinated by the University of Eastern Finland (UEF), in partnership with the Karelia University of Applied Sciences. The funding was provided by the Finnish Ministry of Foreign Affairs.

The project collaboration was a continuation of a long-term one-to-one partnership with these three African universities. They had shown their interest in developing e-learning and library services into their higher education, so these three universities were chosen for the project (see Erkkilä, et al., 2016). The main aim was to improve the infrastructure of the partner universities to provide sustainable, high quality training and pedagogical programs, such as course modules in many areas of public health. It was expected that this project would promote the adoption of modern teaching and evaluation methods by the institutions and staff involved in public health. It was clear that the exploitation of these new methodologies would require support from the library and IT-services.

At the beginning of the project, two young experts from each institution were selected to undertake the training of the trainees (ToT). They were working as academic teachers, librarians and IT-personnel at their universities and they were expected to act as the agents for change in their own institution, i.e. the persons who would transfer their knowledge and skills to other members of their institutions and represent the foundations for their institutionalizing capacity building efforts.

Training of trainees can be divided into five phases:

1. Analysing the current situation and resources in e-learning and supporting services, IT and libraries in the partner institutions

2. Establishing a working platform to allow web-based collaboration

3. Training young experts in the utilization of web-based platforms and contact teaching, modern library and IT services.

4. Implementing in-house services in their home institutions: e-learning courses, learning environments, library and IT services and software implementations 
5. Learning how to work and collaborate with individuals from different cultures.

The changes occurring in the higher education of the partner institutions were evaluated by applying the model of educational change proposed by Fullan (2007). The process of change consists of three phases in this model: initiation, implementation and institutionalization. First, initiation is the process which proceeds after a change; next, implementation describes how the change occurred in practice, finally, institutionalization refers to how the change has been integrated as an ongoing part of the system. The aims of the change process are defined as desirable outcomes, such as improved learning, new skills and attitudes. (Fullan, 2007.) There were different kinds of critical factors involved in each phase of the entire process; these are described in more detail in figure 1.

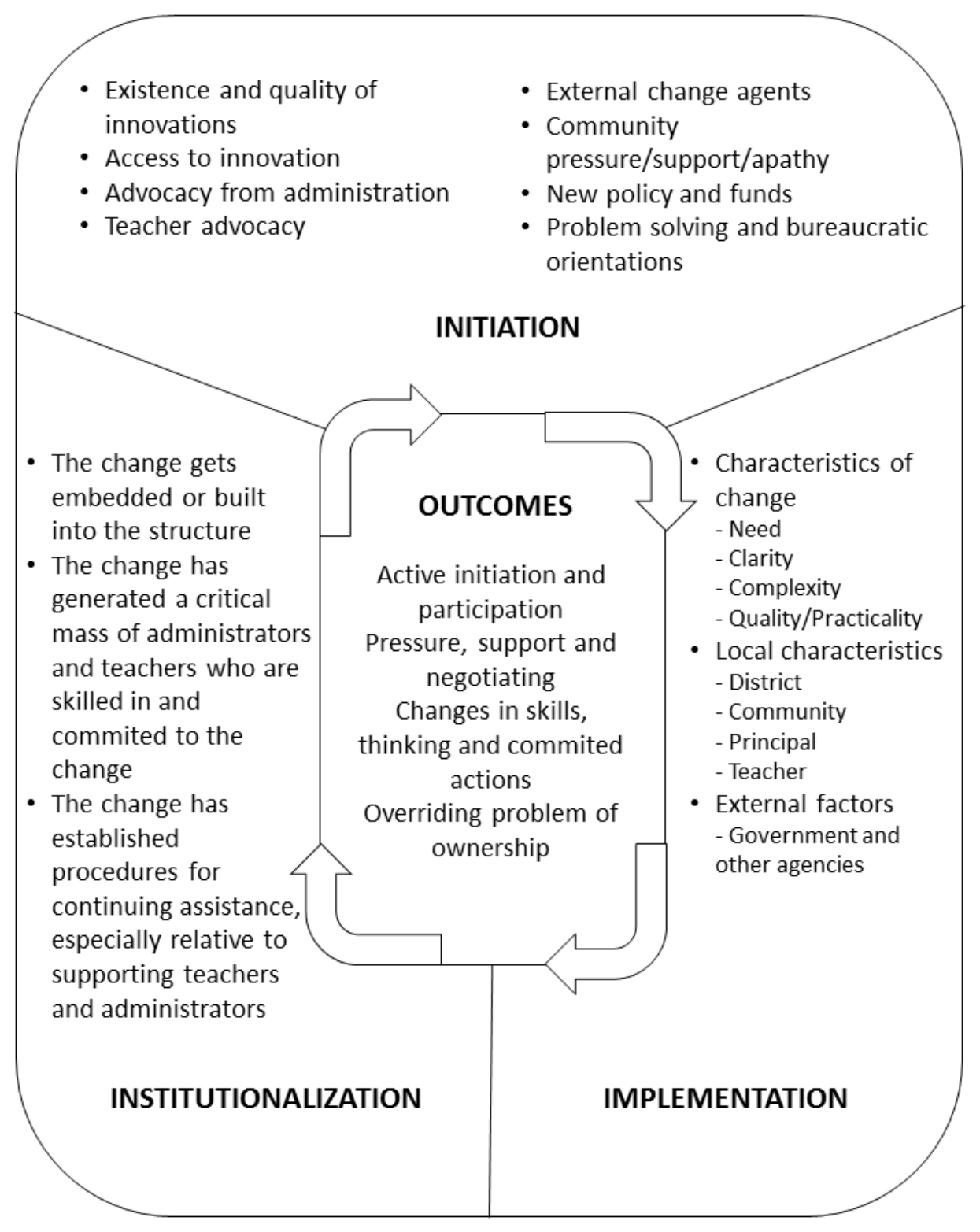

Figure 1: Factors associated with initiation, implementation and institutionalization (modified from Fullan, 2007)

This case study describes and evaluates the educational change during the phases of implementation and institutionalization in three African higher education institutions (HEIs) from the point-of-view of ToTs in the field of e-learning and library services. The following research questions were formulated. What kinds of goals did the ToTs formulate and what did they consider as requirements for the implementation of educational 
change? What kinds of changes happened in ways of thinking and practises of ToTs and their institutes during the project?

\section{Methodology}

\subsection{Data gathering and methods}

This case study describes the findings related to the training of the seven trainees during the project "Improving the Quality of Higher Education in Public Health Sciences II" (HEPHS II) from the period of 20132016 using multiple sources of qualitative data. The ToTs were junior academic staff and support staff, such as lecturers, IT-persons and librarians. Throughout the project, the authors collected written, interviewed and video-taped material made by the participants of the project.

The data-types collected in the period from November 2013 till June 2015:

- Personal Study Plans (PSPs) of the ToTs, workshop in November 2013, $(n=7)$

- Three Moodle-chats with the ToTs were used in preparing for the field-visit and these were evaluated after the visit after training from January 2014 to May 2014, $(n=7)$

- Blogs were used during a training visit to Finland where the participants reflected on what they had learned during their stay in April 2014, $(n=6)$

- A video was made at the end of the visit in which the participants interviewed and filmed each other, describing their opinions about the visit and what they had learned in April 2014, $(n=6)$

- Focus group interview and anticipation dialogues at the end of the project in June $2015,(n=7)$

Personal Study Plans (PSPs) were used as a tool for professional plans and learning reflections during the training. According to Ansela, Haapaniemi and Pirttimäki (2006), a personal study plan can be seen as a personal development path, which tracks the trainee's own study path, holistic growth and development as a lifelong process. In their PSPs, the ToTs were requested to answer what kinds of competencies and expertise they have currently, what kinds of resources and needs they have, and which are their goals and expectations to the training.

Moodle-chats included their needs and expectations of ToTs for the four weeks tailored pedagogical programme. During the programme, ToTs reflected on their learning process and good practices what they have met in blogs and recorded videos. Seven ToTs participated in two hours long focus group interview and anticipation dialogues at the end of project. The group discussed about their own learning, collaboration during the project, challenges they had encountered, current infrastructure in their home institutions, support they had received and knowledge sharing with other personnel within and outside the universities. This discussion was guided, monitored and audio-recorded by the researchers.

According to Seikkula and Arnkil (2014) anticipation dialogue is a premeditated method, where the aim is to "recall" a good future. The first phase is an interview assessing what the participants consider would be the best case scenario; this is monitored by two facilitators; in the second phase, this scenario is supplemented by the creation of a plan. All of the participants were encouraged to think aloud as well as listening to the thoughts of their colleagues. (Seikkula and Arnkil, 2014.) At the beginning of the session, a facilitator provided a short background for discussion; he asked that the ToTs should envisage that they were living in the year 2020 and they should cast their minds back to the start of the project in 2015. The ToTs were divided into two different groups and every participant was interviewed from her/his own perspective on the following themes:

- What good things have happened during the past five years in the library and IT-services on your campus?

- What has made you happy in this positive progress? What did you do so that those things would come to pass? Who helped you?

- What were your worries and what helped in overcoming your worries?

After the interview, all the participants and facilitators discussed their future plans for after the project and what they hoped to achieve on their own campuses and together with partners so that the changes that they hoped to achieve would actually be implemented in the desired manner. All data were collected in English, 
even it was not the native language for participants and researchers. The used gathering methods were planned and implemented by researchers. The main idea to collect this data was to reveal the development of thinking of ToTs and to describe tangible results of project.

\subsection{Data analysis and ethical issues}

The written, interview and video-taped materials were analysed using qualitative content analysis. According to Mayring (2000) this is a method that may be used with different kinds of recorded communication such as transcripts of interviews, protocols of observations, videotapes and documents (Mayring, 2000). Firstly, the whole data was transcribed and the main and generic categories of a categorization matrix were created in a concept-driven or theory-driven way by using the theory of educational change devised by Fullan (2007), where the main categories were initiation, implementation and institutionalization. Subsequently, the data was coded into subcategories in a data-driven manner. Table 1 shows an example of the categorization matrix and the coding of the data.

Table 1: An example of the categorization matrix and the coding of the data. [categories adapted from the educational change model of Fullan, (2007)]

\begin{tabular}{|c|c|c|c|}
\hline Category & Theme & Sub-theme & Related research participant quote \\
\hline \multirow[t]{5}{*}{ Institutionalization } & $\begin{array}{l}\text { Changes in } \\
\text { thinking and } \\
\text { practices of } \\
\text { ToTs and } \\
\text { institution }\end{array}$ & $\begin{array}{l}\text { Sharing } \\
\text { knowledge }\end{array}$ & $\begin{array}{l}\text { "I arranged two sessions for junior staff and teachers" } \\
\text { "I saw how to use different resources like... the use of } \\
\text { database KOHA, which we are deploying now." } \\
\text { "...now I learnt how I (a librarian) can teach literature } \\
\text { and how teacher teaches students..." }\end{array}$ \\
\hline & & Collaboration & $\begin{array}{l}\text { "We are committed to a national nexus of universities." } \\
\text { "I'm lucky that I am a member of... a national } \\
\text { organization for universities." } \\
\text { "Through this collaboration we are able to get even } \\
\text { resources for infrastructure..." }\end{array}$ \\
\hline & & Support & $\begin{array}{l}\text { "How to administration fully get to support the } \\
\text { program, it is hard sometimes..." } \\
\text { "...funding is not so much and we are coping somehow." } \\
\text { "They innovated e-learning unit to the faculty of } \\
\text { medicine." }\end{array}$ \\
\hline & & Policy & $\begin{array}{l}\text { "I communicate with dean and other faculties and put a } \\
\text { proposal for action plan..." } \\
\text { "We did a strategy plan and e-learning was a big } \\
\text { component... It has not provided us an impetus to go } \\
\text { forward." } \\
\text { "We have made some strategies to link more plan } \\
\text { sessions in groups: technical and pedagogical and } \\
\text { library." }\end{array}$ \\
\hline & & Infrastructure & $\begin{array}{l}\text { "Bandwidth is our priority, because it is a big problem." } \\
\text { "We try to develop mobile version" } \\
\text { "So with mobile devices, you have access to resource." } \\
\text { "...resources are limited, it delayed our work } \\
\text { sometimes." }\end{array}$ \\
\hline
\end{tabular}

The data analysis and interpretation process were done according to Elo and Kyngäs (2008). The unit of the code was the statements made by ToTs in their material. The categories for analysis were shaped from the viewpoints of research questions, and only the data that fitted into the matrix was analysed. In this study, this approach made it possible to identify and understand the phases of change in partner institutions, cooperation, development, learning processes of ToTs and the outcomes of the project.

Two analysers were involved in content analysis and they created the categorization, labels and codes in collaboration. The authentic citations and examples of analysis are reported to assure the validity of the content analysis. English was not the native language for participants. All participants provided informed consent to use their verbal and written data in this study. Their anonymity was assured by obscuring their names and other cultural and geographical identifiers. The raw data have been accessed only by the research group. 


\section{Results}

\subsection{Initial situation and pedagogical training}

In the initial phase of the project, the analysis of the current resources and the participants' current expertise about e-learning and library services were assessed both in situ and by interviewing the ToTs. It was noted that the partner universities were very different from each other. For example, their student numbers varied from 1500 to 170000 students; in this study, these three universities are designated as a small (SU), medium (MU) and a large (LU) university. The main resources for e-learning and modern library services are described in table 2.

Table 2: Main resources in the participating HEls for e-learning and modern library services (based on estimation of ToTs)

\begin{tabular}{|c|c|c|c|}
\hline $\begin{array}{c}\text { Universities } \\
\text { Resources }\end{array}$ & $\begin{array}{c}\mathrm{SU} \\
\text { private university }\end{array}$ & $\begin{array}{c}M U \\
\text { private university }\end{array}$ & $\begin{array}{c}L U \\
\text { state-funded university }\end{array}$ \\
\hline The number of students & 1500 & 2500 & 170000 \\
\hline $\begin{array}{l}\text { The number of } \\
\text { computers available for } \\
\text { students }\end{array}$ & 150 & $\begin{array}{l}50 \text { in the Library, } \\
\text { available } 14 \text { hours per } \\
\text { day }\end{array}$ & $\begin{array}{l}250 \text { in the Faculty of } \\
\text { Medicine, use only with } \\
\text { teacher }\end{array}$ \\
\hline $\begin{array}{l}\text { Percentage of laptops } \\
\text { owned by students }\end{array}$ & $30 \%$ & $30 \%$ & $10-15 \%$ \\
\hline $\begin{array}{l}\text { Web-based learning } \\
\text { environment and its use }\end{array}$ & $\begin{array}{l}\text { no web-based learning } \\
\text { environment }\end{array}$ & $\begin{array}{l}\text { Moodle, } 20 \% \text { of teachers } \\
\text { use it, } \\
5-6 \text { courses in health } \\
\text { sciences }\end{array}$ & $\begin{array}{l}\text { Moodle, some courses, } \\
\text { e-exams and material } \\
\text { repository }\end{array}$ \\
\hline WLAN & WLAN $2 \mathrm{Mbit} / \mathrm{s}$ & $\begin{array}{l}\text { Real internet connection } \\
36 \mathrm{Mbit} / \mathrm{s} \text { and WLAN } 2 \\
\mathrm{Mbit} / \mathrm{s}\end{array}$ & no WLAN \\
\hline
\end{tabular}

The greatest challenges in e-learning varied in the three institutions. In LU, the academics had not been trained in how to make the best use of Moodle in their teaching; in that institute, Moodle was mainly used as an archive for material. In $\mathrm{MU}$, there were extensive differences between the departments and e-learning skills were not shared between teachers. Finally SU was not endowed with any kind of web-based learning environment; in this institute not only was there a need to create a web-based learning environment but also the academics who would implement this kind of teaching had to learn the principals of e-pedagogy as well as understanding the technology exploited in e-learning.

Fullan's theory of change (2007), describes the implementation as a changed practice, where characteristics of change existed and some local and external factors affected the initial change. All partner universities were aware at the beginning of the project that they needed modern technology in order to update their education and support services. "Learning and ICT use are two things that cannot be separated if an effecting learning process is to take place..." (IT-person from SU), "For me the biggest experience what I got was that it opened my mind to look at the whole aspect of using technology in teaching... Sometimes when you have resources, but you don't know how to use them, you need other people to see how they are using this kind of resources... (IT-person from MU)

All participants set the following areas as their main goals for implementation 1) to provide high-quality services (ICT and library), support and train to students and academics at the university, 2) to improve collaboration with the administration and 3) to incorporate e-learning into the curricula. In the SU, the main needs were a reliable and an expanded network system through enhanced bandwidth, better co-operation 
with administrative staff and academics and better library services. The needs of the MU involved distinctive and specific needs for ICT from the different departments; the ToTs stated that neither students nor academics had experience of e-learning, a lack of resources and teaching staff, and insufficient local network.

In the LU, the main limitations were of the paucity of technical support and computer labs for such a huge number of students, no staff competent to teach information and e-learning skills and insufficient resources.

The ToTs were asked to consider how they envisaged their academic career and expertise would develop. They compiled their current competencies and needs by using PSPs. Thus, the librarians possessed the competence of professional librarians and they had some educational experience. Instead, the IT-participants had skills for dealing with computer networks, Moodle, general technical support, software and hardware analysis and design. Thus, they needed to expand their pedagogical skills and learn ways to assess know-how.

In spring 2014, ToTs participated in a four week pedagogical training, where they learnt the basics of pedagogy, how to teach in a student-centred way and how to exploit new technology in teaching. "Working in Moodle... it was not only some lectures' material, but good experience on this process, how to do assignments, evaluate... (2nd teacher from LU). "I will introduce some of these new technologies to teachers, when I'm back at home and encourage them to embrace ICT in their classrooms." (Teacher from MU). Especially, librarians and IT-persons claimed that now they better understood teachers and could provide more support than before. They had acquired a mutual language with the academics. "...now I learnt how I can teach literature and how teacher teaches students..." (Librarian from SU), "I am coming from the technological site and getting to the teaching methods and pedagogical issues..., if teachers have problem with technology... when you have an aspect of pedagogy, you can support more." (IT-person from MU).

Additionally, the ToTs understood that they can develop their own teaching or support for teachers by applying e-learning methods and applications in a step-by-step manner. They did not need expensive machines or a large infrastructure, only enthusiasm, belief and the so-called e-attitude. With these attributes they could create their own teaching innovations and that these would be supported by the faculty. "They (administration) think things should be sophisticated and high-technology has to be good, but I see in this project that it should be as simple as possible and applicable... it saves time and efforts, and results can be seen quickly and easily." (1st teacher from LU)

\subsection{Institutionalization of change and received outcomes}

Institutionalization is the term used to describe how the change becomes incorporated into both structure and practice. In this study, institutionalization was considered as the development of changed ways of thinking by the ToTs and changes in the practices within their institutions. Therefore subthemes were formulated to describe the changes - these were named sharing knowledge, collaboration, support, policy and infrastructure. ToTs with a teaching background put their new pedagogical ideas into practice and experimented with student-centred learning. Their initial experiences were encouraging and they became more motivated and confident not only to change their own modes of teaching but also to share their knowledge with their students and other teachers.

“...the pedagogical training, it really added value to my profession, because I have changed it (teach) from teacher-centred to student-centred... more students participated in and they were happy the way that teaching methods changed..." (Teacher from MU), "...students are able to learn independently, so teacher has not to say everything, he can give a chance to learn, collaborate with each other in groups... we also learn from students..." (Teacher from LU)

All of the ToTs prepared a training session on how to create e-learning material for students in their institutions. In LU, they developed a tutorial that was suitable for all of the university's students; in it they described the basics of e-learning. "We make orientation session for students... to show them step by step how to login in the Moodle, ...how to use material, how to go through quizzes, how to make assignments..." (1st teacher from LU)

Some of ToTs noted that this had proved challenging, because it was not easy to change students' attitudes away from traditional teaching towards e-learning. They suspected that students were not ready to take more responsibility for their learning. 
"E-learning is not a way to be lazy. Actually they (students) need work harder, so our aspect is also to arrange training of the students... We try to train blended them (e-learning and contact teaching)... They have to understand the full concept of e-learning." (IT-person from MU)

Additionally, they arranged training for staff and they monitored whether or not the training had been successful in LU. "When I came back from pedagogical training, I arranged two sessions for junior staff and teachers, and tell how to teach in student-centred way and keep several exercises... and l observed during their teaching how the class was running..." ( $2^{\text {nd }}$ teacher from $\left.L U\right)$. Tailored job shadowing provided open tools for librarians, which they transferred with the support of IT-persons to their own institution. "I saw how to use different resources like databank and e-sources and also the use of database KOHA, which we are deploying now." (Librarian from SU) Collaboration increased between support staff and teachers, and together they had greater possibilities to demand changes in their institute. "Through this collaboration we are able to get even resources for infrastructure..." (IT-person from MU). They also had initiated co-operation at the national level and were actively participating in national networks and sharing their knowledge with others. "...l am a member of Telnet, which is a national organization for universities..., one of the projects is e-learning and elibrary at national level." (IT-person from SU), "We are committed to national nexus of universities... This is a commitment between all national universities to use others e-learning courses... we can use others' courses without any fees." (Teacher from LU).

The support from the faculty varied between the universities during the project. Initially, the amount of support was low, but when the faculties started to become aware of the advantages of new technology in teaching and libraries, they invested in new technology, infrastructure and even buildings. "How to administration fully get to support the program, it is hard sometimes... they don't fully understand objectives of these... But when all in the faculty have used e-learning, it mixed all differently. Amazingly, you find that the amount of investment come for human capacity and infrastructure." (IT-person from MU). Nonetheless, even if institutions had invested in infrastructure, there was little funding for support staff. The ToTs tried to prioritize their efforts for e-learning and library services taking into account the current situation. Indeed, some ToTs had enjoyed promotions in their academic career since they were viewed as key agents in promoting educational innovations. "We were lucky to have support from our administration and the faculty... They appreciated what we are doing and support us. They innovated e-learning unit to the faculty of medicine, it was the first time. Then I was choosing to be a director of e-learning centre of university... (1st teacher from LU).

All universities had devised strategies and policy statements involving e-learning and support services. According to the ToT from the MU, the problem seemed to be that HEls did not follow their own mission statements and ToTs did not receive enough support. "We did a strategy plan and e-learning was a big component and I must say that strategy plan has not followed... It has not provided us an impetus to go forward" (IT-person from MU). The changes in the structure of institution caused confusion and the ToTs had faced criticism and suffered slights about their competence. "Administration changed and each one was a critical (for IT-development), but there was said in our strategy that it was my mission to develop e-learning platform. "(IT-person from SU)

In another institute, the ToT had been appointed as director of e-learning centre, and she had emphasized the importance of creating a strategy for e-learning; in fact she was a key person in these efforts. "I communicate with dean and other faculties and put a proposal for action plan..." (1st teacher from LU). ToTs had promoted future collaboration between teachers, IT-support and libraries by planning strategies and action plans together. "We have made some strategies to link more plan sessions in groups: technical, pedagogical and library." (IT-person from SU)

The infrastructure in their institutes had improved somewhat during the time of this project, but it was still a priority in development of e-learning and support services. "Bandwidth is our priority, because it is a big problem." (IT-person from SU), "We have a huge number of students... resources are limited, it delayed our work sometimes." (2nd teacher from LU). At the same time, they had created new learning management systems, databases and mobile applications, because they understood that it was the only way to provide a modern e-learning and library environment for students and academics. "We try to develop mobile version, 
because we have seen that typically they (students) have smartphones, that's why we prove it wireless." (ITperson from MU), "The most important is that we saw that this is possible." (IT-person from SU).

\section{Discussion}

Our paper describes an educational change occurring in three African higher education institutions (HEIs) in elearning and library services from the point-of-view of the ToTs. The theory of the educational change devised by Fullan (2007) was used as the theoretical framework. The deployment of e-learning and modern library services need clear goals, vision and support from institutions. The results demonstrated that all of the participating institutions had taken the first step to integrating e-learning and modern library services so that it had become a part of their daily practices. The key to success was the enthusiasm of both academics and support staff who were ready to take responsibility for development and implementation. However, even enthusiasm is not sufficient without support from the university administration. These results are in parallel with the study by $\mathrm{Ng}^{\prime}$ ambi and Bozalek (2013), where the personal enthusiasm of the agents of change about these emerging novel technologies was the main motivator for their deployment. Ng'ambi and Bozalek (2013) presented a model where formal leadership was needed in order to exploit and support informal change agents in the adoption of innovations in higher education. In our study, the ToTs had set their own goals at the beginning of their training so that they were able to develop exactly those aspects of library and information technology that would be optimal for their own institution. They were anxious to deliver modern services for students and academics, and to be able to provide support and training on a regular basis. Additionally, they were enthusiastic that e-learning would become better integrated into the curricula.

All institutions faced challenges to implement these reforms and the ToTs recognized these problems. The lack of infrastructure and support services, inadequate co-operation with other academics and administration and the lack of awareness about the advantages of e-learning by students and academics were the obstacles which had to be confronted and resolved. The results demonstrated that long-term mutual training for staff on elearning and library services can be considered as an agent for change in their institutions, but it demands collaboration and support from other teachers and support staff.

In this case study, pedagogy was a key to achieving a change. All ToTs participated in a four-week pedagogical training and during that time, they began to understand each other better e.g. the goals of the other ToTs and what was meant by good library and IT-services. They found a common language with which to collaborate and promote educational change.

The main issues in institutionalization were knowledge sharing, collaboration, support, policy and infrastructure. E-learning and modern library and IT-services were recognized as being essential to all institutions and their structure. According to Fullan (2007), the change can only be built into the structure of institutions through policy and only generated when there is a critical mass of administrators and teachers who are skilled and committed to change. Thus, the local training for academics and students capable of training their own staff was a key to success. ToTs were provided with pedagogical know-how and taught the skills allowing them to share their knowledge with others. Academics and students were provided with support by ToTs and they were eager to start e-learning and the use of modern library services. The trainings provided a foundation so that a practical reforms could be made e.g. they encouraged the committed academics to work together as agents of change.

In this study, all of the participating HEls had devised strategies and issued policy statements about e-learning and support services, but their words had not always been translated into action. The ToTs were aware of this contradiction; some of them thought that it was a personal failure that even though they were following the stated aims of their institute, the administration had not understood or supported their efforts. This result differed from the study of Louvel (2013) where academics did not follow some predetermined plan in a change situation. One reason for this discrepancy is that here the ToTs were motivated, even enthusiastic, about adopting the new technology in their HEl. According to $\mathrm{Ng}^{\prime}$ ambi and Bozalek (2013) these types of individuals should be viewed as executers who would be most likely to succeed in implementing innovative practices.

Both supportive policies and executors are needed when embarking on changing the policies of HEls. 
It was interesting to examine how the infrastructure had developed in HEls, even in those cases where the resources remained at the same level as they had been at the beginning of the project. The ToTs were well aware of the needs of academics and students and were able to prioritize their developmental work to answer these needs. They were able to develop new systems, services and applications and they understood that progress can occur in a step by step manner without huge investments in infrastructure. Clearly, small steps were better than no steps at all. In many studies (e.g. Ng'ambi and Bozalek, 2013; Gupta, et al., 2017), a lack of sufficient infrastructure has been considered as the greatest institutional obstacle to deployment of new technology and services, but in this study it was noted that the development of innovations could be traced to certain key individuals, men and women of vision who understood the real needs of their HEls and developed them steadfastly. When other academics and administration saw the promising results, the innovators were more likely to receive more resources from their HEls. In summary, there are three foundation stones to developing e-learning and services in HEls - visionary strategies, realistic policies and enthusiastic executors.

\section{Conclusion}

This article focused on the presentation of the empirical results from the participating ToTs in this project. Its main purpose was to describe and evaluate whether there had been educational change in e-learning and library services assessed via implementation and institutionalization in three African higher education institutions (HEls).

Based on our experiences, we conclude that by the selection of enthusiastic agents of change and teaching them about up-to-date aspects of higher education including modern teaching technologies, one can innovate the practices of academic institutions. We noted that the most crucial aspect in achieving a positive outcome was that there had to support and a strategic commitment from the host institution.

Perhaps the most interesting finding was that an awareness of modern pedagogic skills and learner-centred education are crucial not only for academic teachers but especially for the support service staff. These skills make possible knowledge transfer throughout the home institution. It is important that all the individuals in an academic institution speak a common language and share the same value base and all are supporting the learning of the HEl's students.

\section{References}

Adams, T., and de Wit, H., 2011. Global competition in Higher Education. A comparative study of policies, rationales and practices in Australia and Europe. In H. de Wit, ed. 2011. Trends, issues and Challenges in Internationalisation of Higher Education. pp. 29-38. Centre for Applied Research on Economics and Management, School of Economics and Management of the Hogeschool van Amsterdam.

African Union (AU), 2014. AU outlook on education report. Continental Report. African Union, Department of Human Resources, Science and Technology (HRST).

Altbach, P., Reisberg, L. and Rumbley, L., 2009. Trends in global Higher Education: tracking an academic revolution. A Report Prepared for the UNESCO 2009 World Conference on Higher Education. United Nations Educational, Scientific and Cultural Organization (UNESCO), France.

Ansela, M., Haapaniemi, T. and Pirttimäki, S., 2006. Personal study plans for university students. A guide for Study Counsellors Learning Centre. University of Kuopio.

Association for the Development of Education in Africa (ADEA), 2013. ADEA medium-term Strategic Plan 2013-2017. Education, skills and qualifications for sustainable development in Africa.

Courtney, K., 2013. Adapting higher education through changes in academic work. Higher Education Quarterly, 67 (1), pp. 40-55.

Elo, S., and Kyngäs, H., 2008. The qualitative content analysis process. Journal of Advanced Nursing, 62 (1), pp. 107-115.

Erkkilä, A., Haaranen, A., Kauhanen, J., Khan, S. and Saarti, J. eds., 2016. Better learning for better health: HEI-ICI projects and practices. Publications of the University of Eastern Finland. General Series, 18. Kuopio: University of Eastern Finland.

Fullan, M., 2007. The new meaning of educational change. Fourth Edition. New York, Teachers College Press, London, Routledge. U.S.A.

Gupta, M., Marsden, S., Oluka, T., Sharma, R. and Lucas, H., 2017. Lessons learned from implementing e-learning for the education of health professionals in resource-constrained countries. The Electronic Journal of e-Learning, 15 (2), pp. 144-155.

Kindelan, P. and Martin, A., 2014. Contextualising change through a common strategy: lecturers' perceptions and key role in supporting academic reform. International Review of Education, 60 (1), pp. 33-50.

Majgaard, K. and Mingat, A., 2012. Education in sub-Saharan Africa. A comparative analysis. Washington, D.C. World Bank. 
Mapesela, M. and Hay, D., 2006. The effect of change and transformation on academic staff and job satisfaction: A case of a South African University. Higher Education, 52 (4), pp. 711-747.

Marginson, S. and van der Wende, M., 2007. Globalisation and Higher Education. OECD Education Working Papers, No. 8. OECD Publishing.

Mayring, P., 2000. Qualitative content analysis. Forum Qualitative Sozialforschung / Forum: Qualitative Social Research, 1 (2), Art. p.20.

Ndulu, B., 2014. Human capital flight: stratification, globalization and the challenges to tertiary education in Africa. Washington, DC: World Bank Group.

Ng'ambi, D. and Bozalek, V., 2013. Leveraging informal leadership in higher education institutions: A case of diffusion of emerging technologies in a southern context. British Journal of Educational Technology, 44 (6), pp. 940-950.

Sall, H.N. and Ndjaye, B.D., 2007. Higher Education in Africa: between perspectives opened by the Bologna Process and the commodification of education. European Education, 39 (4), Winter 2007-8, pp. 43-57.

Salmon, G., 2005. Flying not flapping: a strategic framework for e-learning and pedagogical innovation in higher education institutions. ALT-J, Research in Learning Technology, 13 (3), pp. 201-218.

Seikkula, J. and Arnkil, T-E., 2014. Open dialogues and anticipations. Respecting otherness in the present moment. National Institute for Health and Welfare. Juvenes Print - Finnish University Print Ltd, Tampere, Finland.

Souter, D., Adam, L., Butcher, N., Sibthorpe, C. and Tusubira, T., 2014. ICTs for education in Africa. [online]. World Bank, Washington, DC. < https://openknowledge.worldbank.org/handle/10986/19024 License: CC BY 3.0 IGO> [Accessed 30 November 2018]

Vögtle, E.M. and Martens, K., 2014. The Bologna Process as a template for transnational policy coordination. Policy Studies, 35 (3), pp. 246-263.

Ylijoki, O-H., 2014. University under structural reform: a micro-level perspective. Minerva 52, pp. 55-75. 